\title{
Proteomic identification of secreted proteins of Propionibacterium acnes
}

\author{
Carsten Holland ${ }^{1}$, Tim N Mak' ${ }^{1}$, Ursula Zimny-Arndt ${ }^{2}$, Monika Schmid ${ }^{2}$, Thomas F Meyer ${ }^{1}$, Peter R Jungblut ${ }^{2}$, \\ Holger Brüggemann ${ }^{1 *}$
}

\begin{abstract}
Background: The anaerobic Gram-positive bacterium Propionibacterium acnes is a human skin commensal that resides preferentially within sebaceous follicles; however, it also exhibits many traits of an opportunistic pathogen, playing roles in a variety of inflammatory diseases such as acne vulgaris. To date, the underlying disease-causing mechanisms remain ill-defined and knowledge of $P$. acnes virulence factors remains scarce. Here, we identified proteins secreted during anaerobic cultivation of a range of skin and clinical P. acnes isolates, spanning the four known phylogenetic groups.

Results: Culture supernatant proteins of $P$. acnes were separated by two-dimensional electrophoresis (2-DE) and all Coomassie-stained spots were subsequently identified by MALDI mass spectrometry (MALDI-MS). A set of 20 proteins was secreted in the mid-exponential growth phase by the majority of strains tested. Functional annotation revealed that many of these common proteins possess degrading activities, including glycoside hydrolases with similarities to endoglycoceramidase, $\beta$-N-acetylglucosaminidase and muramidase; esterases such as lysophospholipase and triacylglycerol lipase; and several proteases. Other secreted factors included Christie-AtkinsMunch-Petersen (CAMP) factors, glyceraldehyde 3-phosphate dehydrogenase (GAPDH), and several hypothetical proteins, a few of which are unique to $P$. acnes. Strain-specific differences were apparent, mostly in the secretion of putative adhesins, whose genes exhibit variable phase variation-like sequence signatures.

Conclusions: Our proteomic investigations have revealed that the $P$. acnes secretome harbors several proteins likely to play a role in host-tissue degradation and inflammation. Despite a large overlap between the secretomes of all four $P$. acnes phylotypes, distinct differences between predicted host-tissue interacting proteins were identified, providing potential insight into the differential virulence properties of $P$. acnes isolates. Thus, our data presents a rich resource for guiding much-needed investigations on $P$. acnes virulence factors and host interacting properties.
\end{abstract}

\section{Background}

The Gram-positive skin commensal Propionibacterium acnes is ubiquitously present on human skin. It has been speculated that this bacterium contributes to healthy skin by deterring the colonization of severe pathogens [1,2]; however, it is most well known for its role in skin disorders such as acne vulgaris [3,4]. Acne, a multifactorial disorder related to the formation of comedones, hormonal stimulation, bacterial colonization and the host inflammatory response, is an extremely

\footnotetext{
* Correspondence: brueggemann@mpiib-berlin.mpg.de

'Department of Molecular Biology, Max Planck Institute for Infection Biology, Berlin, Germany

Full list of author information is available at the end of the article
}

common condition affecting approximately $80 \%$ of adolescents. Despite intense research effort, the precise role of $P$. acnes in acne formation is still unclear [5-7].

In addition to acne, $P$. acnes has been frequently associated with a variety of inflammatory diseases, including prosthetic joint infections, shunt-associated central nervous system infections, endocarditis, sarcoidosis, endophthalmitis, osteomyelitis, allergic alveolitis, pulmonary angitis, acne inversa (alias hidradenitis suppurativa), and the SAPHO (synovitis, acne, pustulosis, hyperostosis, osteitis) syndrome [8-10]. This bacterium is also a common isolate of prostatic glands from patients with prostate inflammation $[11,12]$. Interestingly, the role of $P$. acnes in the development of prostate
C Biomed Central

C 2010 Holland et al; licensee BioMed Central Ltd. This is an Open Access article distributed under the terms of the Creative Commons Attribution License (http://creativecommons.org/licenses/by/2.0), which permits unrestricted use, distribution, and reproduction in any medium, provided the original work is properly cited. 
cancer through an inflammatory mechanism is currently a subject of much speculation [12-14].

The prevalence of $P$. acnes in the above-mentioned conditions suggests that this bacterium is an etiological agent of infection and that it possesses an elevated pathogenic potential. P. acnes has been shown to exhibit haemolytic and cytotoxic activities $[15,16]$ as well as extensive immunostimulatory activity and complement activation [6,17-20]. P. acnes isolates differ in their virulence properties, such as in their ability to trigger production of proinflammatory cytokines/chemokines in infected keratinocytes [21,22]. The genetic basis for this has not yet been studied in detail. To date four phylogenetic groups of $P$. acnes have been described, designated types IA, IB, II and III, based on sequence differences in two genes, namely $\operatorname{rec} A$ and tly $[23,24]$.

Despite the apparent role of $P$. acnes in disease formation, information on putative pathogenic traits and antigenic substances of this bacterium is scarce. The complete genome sequence of a cutaneous type IB isolate of $P$. acnes (strain KPA171202) provided insights into the pathogenic potential of $P$. acnes, revealing numerous gene products with putative host tissue-degrading activities as well as predicted cell wall-associated and secreted proteins, the presence or activity of which might be involved in triggering host tissue inflammation [25]. Some of these proteins are differentially expressed among $P$. acnes isolates and were shown to be immunoreactive [26].

To shed light on the biological relevance of predicted genes from the genome sequence, we used a combination of two-dimensional electrophoresis (2-DE) and matrix-assisted-laser-desorption/ionization mass spectrometry (MALDI-MS) to identify proteins secreted by $P$. acnes. Isolates representing all four phylotypes were investigated. Several hydrolases and putative virulence factors were secreted by all strains tested. These factors are potential host-interacting factors, likely important in inflammatory responses to $P$. acnes, as observed in acne vulgaris. Thus, our data provide a basis to guide further in-depth studies on individual factors.

\section{Results and Discussion}

\section{Choice of $P$. acnes strains}

We selected five strains of $P$. acnes for analysis of their secreted proteins. These strains, representing all known $P$. acnes phylotypes, i.e. types IA, IB, II and III, were isolated from a range of tissue sites: a type II skin acne isolate (strain 329); a type III strain isolated from a postoperative prosthetic joint infection (strain 487); a type IA strain isolated from a pleuropulmonary infection (strain 266); and two type IB strains: a skin isolate for which the genome sequence is available (strain KPA171202; KPA); and an isolate from a cancerous prostate (strain $\mathrm{P} 6$ ).

\section{2-DE-MALDI-MS analysis of $P$. acnes culture supernatants} To identify proteins secreted by $P$. acnes using proteome analysis, we cultured each strain under anaerobic conditions in brain heart infusion (BHI) broth, previously used for secretome analyses [27]. Growth curves were generated (data not shown) and culture supernatants were harvested in the mid-exponential phase. Precipitated proteins from supernatants were separated by 2 $\mathrm{DE}$ and Coomassie stained, generating reproducible secretomes of all five strains tested (Fig. 1A-E and additional file 1). All visible protein spots were analyzed by MALDI-MS and searched against the NCBI non-redundant database, which included (at the time of analysis) the genome sequence of the type IB strain KPA and the partial genome sequence of the type IA strain SK-137.

The identified proteins for each strain, with molecular weights, isoelectric points, Mascot scores and sequence coverage are listed in additional file 2 . In total, 64, 63, 54,30 , and 28 protein spots for $P$. acnes strains 266 , KPA, P6, 329 and 487, respectively, were unambiguously identified and assigned to database entries. Several proteins occurred in spot series, representing different protein species of the same protein. Post-translational modifications are a likely explanation, resulting in altered molecular masses and/or isoelectric points [28]. A few MS spectra originating from secreted proteins of strain 329 could not be assigned to any database entry (Fig. 1D, spots 39-41), indicating that these proteins are strain-specific. The inability to identify these proteins also reflects the absence of genome sequence data from type II and type III strains; only genome sequences from type I strains are currently available.

\section{Twenty commonly secreted proteins of $P$. acnes}

The identified proteins secreted by the five strains tested were assigned to the reference KPA genome (Fig. 2, additional file 2). A set of 20 proteins was secreted by at least three of the five strains, including eight proteins secreted by all strains (Table 1). All 20 proteins were secreted by the P6 strain, whereas 19 (95\%), 15 (75\%), $15(75 \%)$ and $12(60 \%)$ of these proteins were secreted by the KPA, 266, 329 and 487 strains, respectively. We cannot exclude, however, that proteins secreted at lower levels were missed by our approach, as the amount of secretion varied between the strains and the sensitivity of the Coomassie stain is limited to the $100 \mathrm{ng}$ range.

All 20 proteins except one, glyceraldehyde 3-phosphate dehydrogenase (GAPDH), carried a secretion signal in its $\mathrm{N}$-terminus. $P$. acnes has a general secretion (Sec)/signal recognition particle (SRP) and a twin-arginine translocation (TAT) secretion system. Other secretion systems have not been reported for P. acnes, and rescanning of the genome sequence gave no indication that additional ones exist. 
A

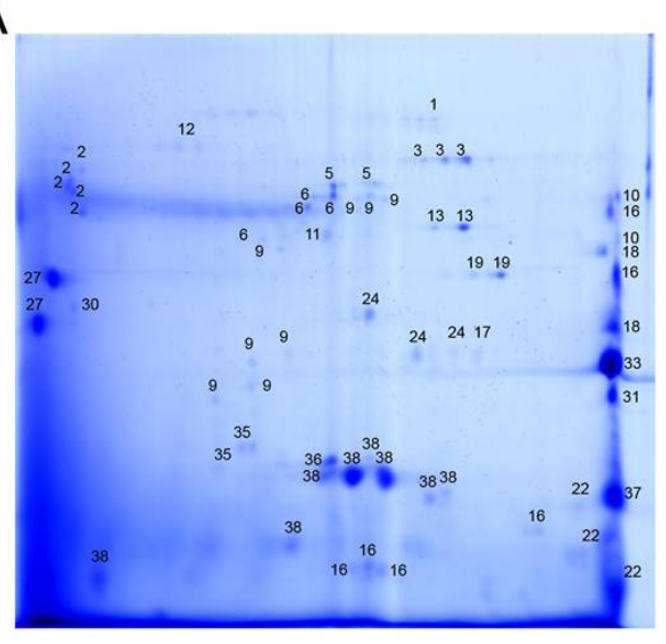

C

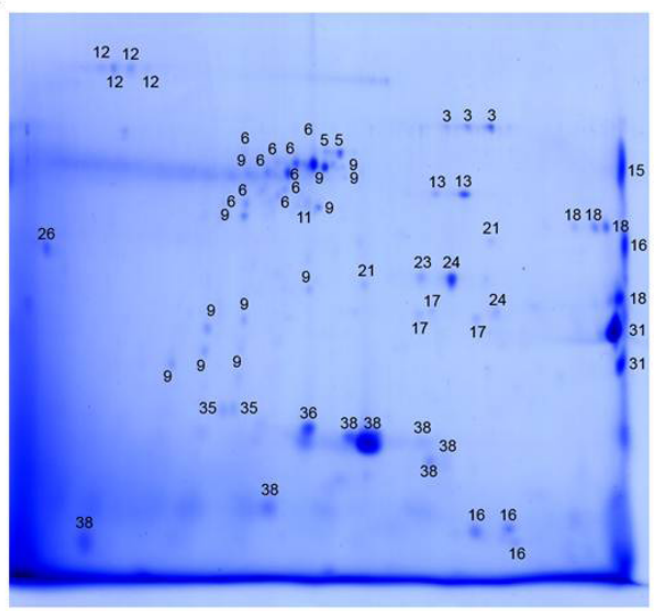

E

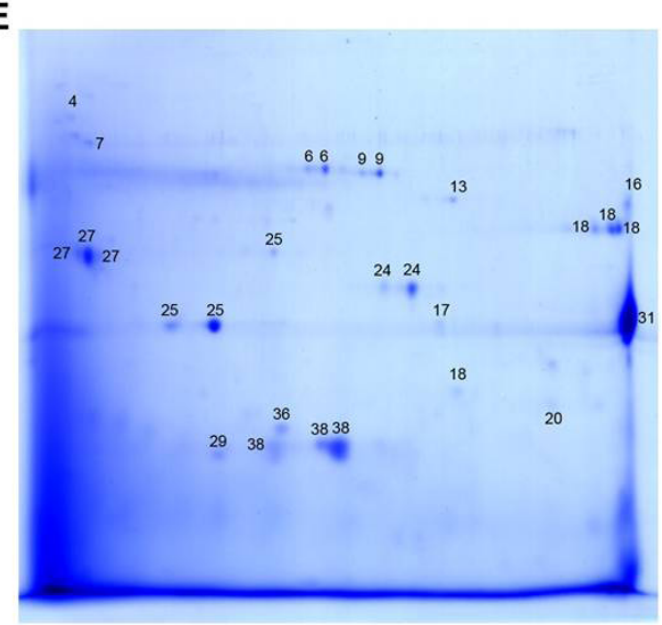

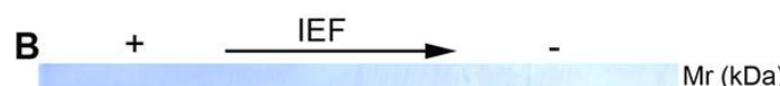

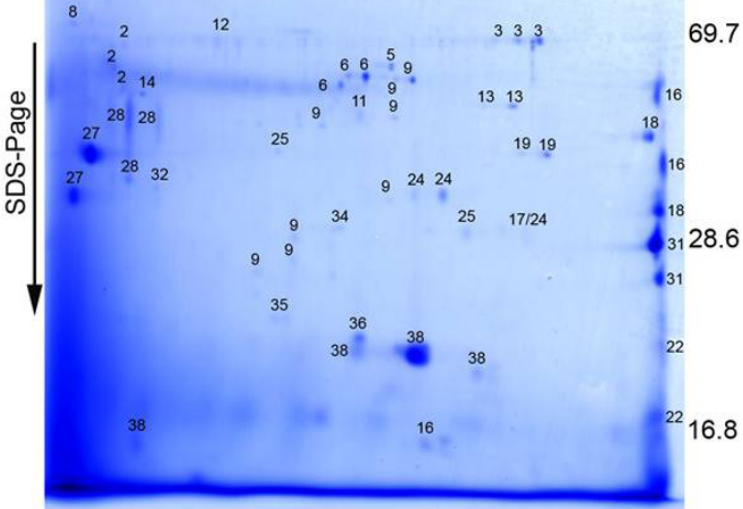

D

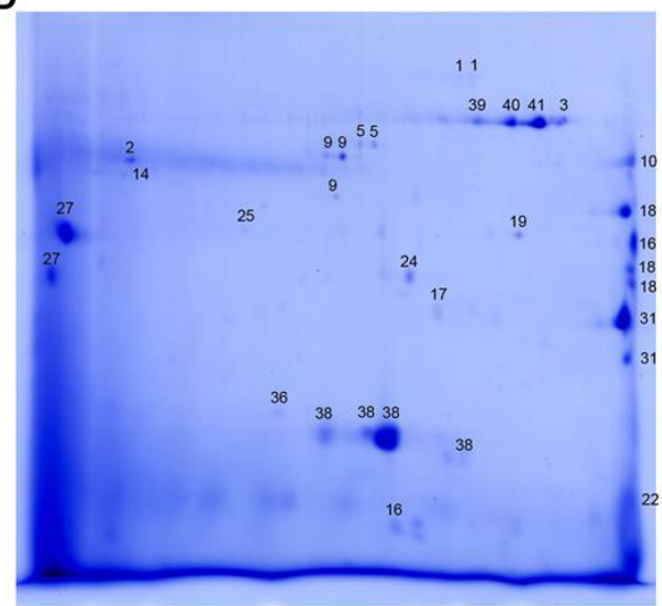

69.7

Figure 1 2-DE of $\boldsymbol{P}$. acnes culture supernatants. Bacteria were grown in $\mathrm{BH}$ medium to an $\mathrm{OD}_{600}$ of 0.6 . Supernatants were harvested and precipitated. Protein samples $(200 \mu \mathrm{g})$ from each strain were separated on 2-DE gels and visualized by staining with Coomassie Brilliant Blue G250. The following strains were used: (a) KPA171202 (type IB); (b) P6 (type IB); (c) 266 (type IA); (d) 329 (type II); (e) 487 (type III). Information about the identified protein spots is provided in additional file 2 . 


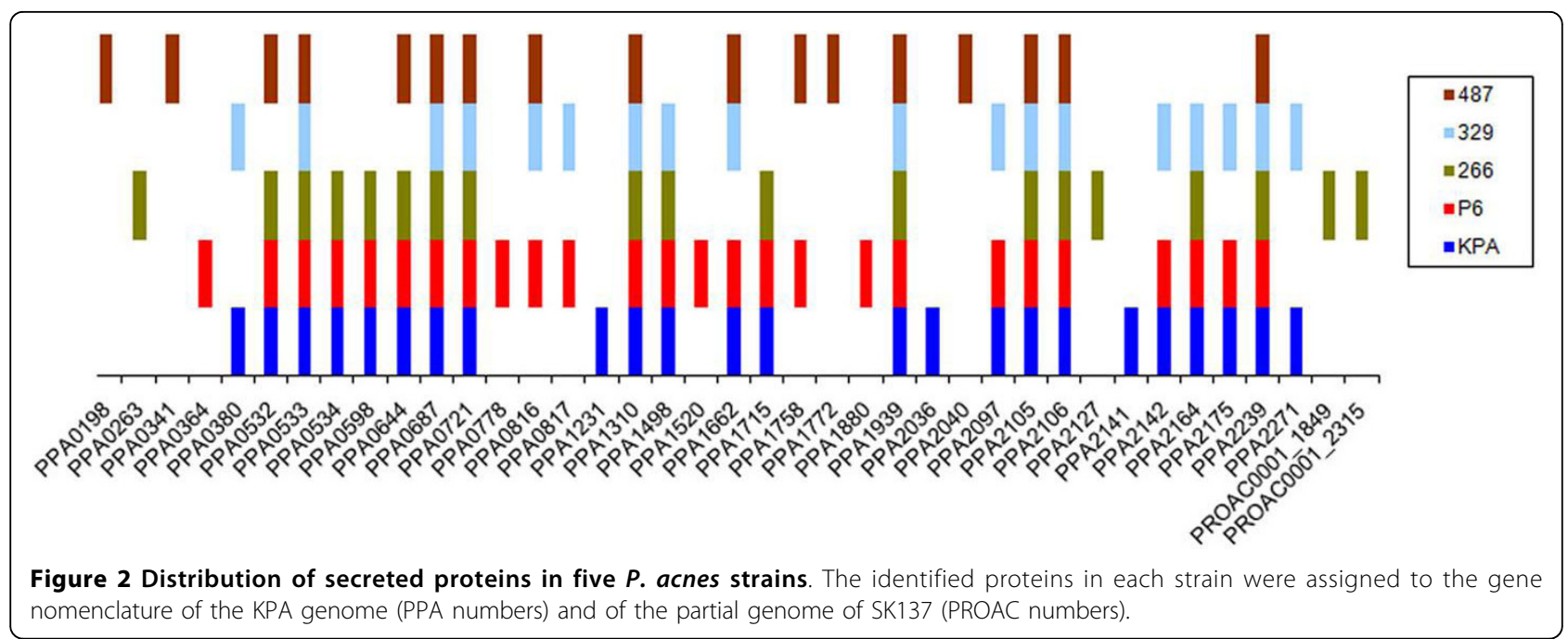

\section{Hydrolytic enzymes are secreted by $P$. acnes}

To gain insight into the biological functions of the 20 commonly secreted proteins, re-annotation was performed based on similarity searches against protein sequence and protein-domain/-family databases (Table 1). Many of the secreted proteins were found to have predicted hydrolytic activities: two genes (PPA0644 and PPA2106) are predicted endo-glycoceramidases, sharing $42 \%$ identity on the protein level. Although their substrate specificities are unknown, PPA0644 and PPA2106 share $27 \%$ and $30 \%$ protein identity, respectively, with the characterized and structurally analyzed endo-glycoceramidase II from Rhodococcus sp., which hydrolyzes glycosidic linkages between the oligosaccharide and ceramide moieties of gangliosides [29]. Another secreted protein, PPA2164, a glycoside hydrolase family 3 protein, shares $31 \%$ identity on the protein level with NagZ (formerly $\mathrm{YbbD}$ ) of $B$. subtilis. NagZ is a $\beta$-N-acetylglucosaminidase involved in the peptidoglycan recycling pathway; it cleaves the terminal non-reducing $\mathrm{N}$-acetylglucosamine of muropeptides [30]. P. acnes also secreted a putative lysozyme (PPA1662) which is $47 \%$ identical on the protein level to the muramidase from Streptomyces coelicolor. This muramidase not only cleaves the $\beta$-1,4-glycosidic bond between $\mathrm{N}$-acetylmuramic acid and $\mathrm{N}$-acetylglucosamine units, but also exhibits $\beta$-1,4$\mathrm{N}, 6-\mathrm{O}$-diacetylmuramidase activity, enabling this enzyme to degrade Staphylococcus aureus cell walls [31]. Whether PPA1662 is an autolytic lysozyme involved in cell wall turnover has still to be elucidated. However, the peptidoglycan of $P$. acnes contains non- $\mathrm{N}$-acetylated glucosamine residues and is therefore resistant to lysozyme [32]. We speculate that PPA1662 has a different substrate specificity, acting on non-N-acetylated peptidoglycan, or, alternatively, it acts as a defense system against competing bacteria on the skin.
Two strains, KPA and 329, secreted a hyalorunate lyase (PPA0380), confirming previous investigations on a $P$. acnes protein with hyalorunate lyase activity $[33,34]$. Preliminary functional characterization revealed that the enzyme exerted activity against chondroitin 4- and 6-sulphates but not against dermatan sulphate [33]. In accordance, the closest characterized homolog, the chondroitin lyase of Arthrobacter aurescens (37\% protein identity to PPA0380) acts on chondroitin sulfate but not on dermatan sulfate [35]. Similar to other chondroitin lyases, it is capable of cleaving hyaluronan, a non-sulfated glycosaminoglycan and a major component of the extracellular matrix of connective tissues.

Consistent with the known lipolytic activity of $P$. acnes [36], we identified lipolytic enzymes in the secretory fraction, including the previously characterized triacylglycerol lipase, designated glycerol-ester hydrolase A (GehA; PPA2105). GehA is recognized as one of the virulence factors involved in the pathogenesis of acne [37-39], and is thought to be the main enzyme responsible for the hydrolysis of sebum triacylglycerides, resulting in the release of glycerol and free fatty acids. The released fatty acids are thought to be inflammatory; they favor ductal hypercornification and increase adhesion between $P$. acnes and cells of the hair follicle, promoting colonization of P. acnes and biofilm formation [37,40-42]. Furthermore, GehA itself is a strong chemotactic factor [43]. Other secreted esterases identified include a putative lysophospholipase (PPA2142) and a putative phosphoesterase (PPA1498) with unknown specificities. Proteases, another class of secreted hydrolases, were also detected, e.g. a peptidase S8/S53 family protein (PPA0598) among others; their substrate specificities remain to be elucidated. 
Table 1 Twenty proteins constitute the common secretome of $P$. acnes

\begin{tabular}{|c|c|c|c|c|c|}
\hline $\begin{array}{l}\text { Gene } \\
\text { ID }\end{array}$ & Updated annotation & $\begin{array}{l}\text { Protein family/domains/origin of closest } \\
\text { ortholog }\end{array}$ & $\begin{array}{l}\text { Secretion } \\
\text { signal }^{\mathrm{a}}\end{array}$ & $\begin{array}{l}\text { Phylo- } \\
\text { type }\end{array}$ & $\begin{array}{l}\text { Semi-quantification }{ }^{\mathrm{b}} / \\
\text { comments }\end{array}$ \\
\hline PPA0532 & conserved hypothetical protein & Corynebacterium & SP, TAT & $\begin{array}{l}|A,| B, \\
I I \mid\end{array}$ & ++ \\
\hline PPA0533 & conserved hypothetical protein & Corynebacterium & SP & $\begin{array}{l}|A,| B, \\
\|,|| \mid\end{array}$ & + \\
\hline PPA0534 & conserved hypothetical protein & Corynebacterium & $\mathrm{SP}$ & $I A, I B$ & + \\
\hline PPA0598 & putative protease & $\begin{array}{l}\text { peptidase } \mathrm{S} 8 / \mathrm{S} 53 \text { superfamily; } \\
\text { Arthrobacter }\end{array}$ & SP, (TAT) & $I A, I B$ & + \\
\hline PPA0644 & putative endo-glycoceramidase & $\begin{array}{l}\text { cellulase, glycoside hydrolase family } 5 \text {; } \\
\text { Corynebacterium }\end{array}$ & (SP), TAT & $\begin{array}{l}\mid \mathrm{A}, \mathrm{IB}, \\
\mathrm{II}\end{array}$ & $\begin{array}{l}++/ 42 \% \text { identity to } \\
\text { PPA2106 }\end{array}$ \\
\hline PPA0687 & CAMP2 & $\begin{array}{l}\text { CAMP factor superfamily; Mobiluncus curtisii, } \\
\text { Streptococcus }\end{array}$ & SP & $\begin{array}{l}|\mathrm{A},| \mathrm{B}, \\
\|, \mid \mathrm{II}\end{array}$ & +++ \\
\hline PPA0721 & $\begin{array}{l}\text { putative invasion-associated } \\
\text { protein; NIpC/P60 family }\end{array}$ & $\begin{array}{l}\text { NlpC/P60 family; } \\
\text { Kribbella flavida, Streptomyces }\end{array}$ & SP, TAT & $\begin{array}{l}I A, I B, \\
\|, I\|\end{array}$ & $\begin{array}{l}+++/ \mathrm{NlpC} / \mathrm{P} 60 \text { is found in } \\
\text { cell wall hydrolases }\end{array}$ \\
\hline PPA0816 & $\begin{array}{l}\text { glyceraldehyde 3-phosphate } \\
\text { dehydrogenase }\end{array}$ & GAPDH & no & $\mid \mathrm{B}, \mathrm{II}, \mathrm{II}$ & + \\
\hline PPA1310 & putative protease & $\begin{array}{l}\text { PDZ superfamily; } \\
\text { Kribbella flavida, Streptomyces }\end{array}$ & $\begin{array}{l}\text { Internal SP } \\
\text { (wrong N- } \\
\text { terminus) }\end{array}$ & $\begin{array}{l}|\mathrm{A},| \mathrm{B}, \\
\mathrm{II}, \mathrm{II}\end{array}$ & $\begin{array}{l}+/ P D Z \text { is a signaling } \\
\text { domain }\end{array}$ \\
\hline PPA1498 & putative phosphoesterase & $\begin{array}{l}\text { metallo-dependent phosphatase superfamily; } \\
\text { Rhodococcus }\end{array}$ & TAT & $\begin{array}{l}\mid \mathrm{A}, \mathrm{IB}, \\
\|\end{array}$ & + \\
\hline PPA1662 & putative lysozyme & $\begin{array}{l}\text { CH-type (chalaropsis-type) lysozyme, glycoside } \\
\text { hydrolase family 25; Streptomyces }\end{array}$ & SP, TAT & $\mid \mathrm{B}, \mathrm{II}, \mathrm{II}$ & +++ \\
\hline PPA1715 & $\begin{array}{l}\text { hypothetical protein, specific to } \\
\text { P. acnes }\end{array}$ & & $\mathrm{SP}$ & $I A, I B$ & +/17 PT repeats \\
\hline PPA1939 & $\begin{array}{l}\text { hypothetical protein, specific to } \\
\text { P. acnes }\end{array}$ & & SP & $\begin{array}{l}|\mathrm{A},| \mathrm{B}, \\
\mathrm{II}, \mathrm{II}\end{array}$ & +++ \\
\hline PPA2097 & $\begin{array}{l}\text { putative } 5^{\prime} \text {-nucleotidase, } \\
\text { metallo-phosphoesterase }\end{array}$ & $\begin{array}{l}\text { UshA (5'-nucleotidase } / 2 \text { ', } 3^{\prime} \text {-cyclic } \\
\text { phosphodiesterase and related esterases); Jonesia } \\
\text { denitrificans }\end{array}$ & SP, TAT & $\mid \mathrm{B}, \mathrm{I}$ & + \\
\hline PPA2105 & triacylglycerol lipase & $\begin{array}{l}\text { lipase class 2, esterase/lipase superfamily; } \\
\text { Rhodococcus }\end{array}$ & $\mathrm{SP}$ & $\begin{array}{l}|\mathrm{A},| \mathrm{B}, \\
\|,|| \mid\end{array}$ & ++ \\
\hline PPA2106 & putative endoglycoceramidase & $\begin{array}{l}\text { cellulase, glycoside hydrolase family } 5 \text {; } \\
\text { Nocardioides }\end{array}$ & $\mathrm{SP},(\mathrm{TAT})$ & $\begin{array}{l}|A,| B, \\
\|,|| \mid\end{array}$ & +/42\% identity to PPA0644 \\
\hline PPA2142 & putative lysophospholipase & $\begin{array}{l}\text { alpha/beta-hydrolase superfamily, PldB; } \\
\text { Corynebacterium }\end{array}$ & SP, TAT & $\mid \mathrm{B}, \mathrm{I}$ & + \\
\hline PPA2164 & $\begin{array}{l}\text { putative beta-N-acetyl- } \\
\text { glucosaminidase }\end{array}$ & glycoside hydrolase family 3; Arthrobacter & $\mathrm{SP}$ & $\begin{array}{l}|A,| B, \\
\|\end{array}$ & ++ \\
\hline PPA2175 & $\begin{array}{l}\text { hypothetical protein, with } \mathrm{SH} 3 \\
\text { and RlpA domains, specific to } P \text {. } \\
\text { acnes }\end{array}$ & $\begin{array}{l}\text { SH3 (type 3) domain; peptidoglycan-binding } \\
\text { domain; C-terminus: DPBB_1 (RlpA-like double-psi } \\
\text { beta-barrel) }\end{array}$ & SP, TAT & $|\mathrm{B}| \mid$, & $\begin{array}{l}+++/ \text { SH3: Src homology } 3 \\
\text { domain }\end{array}$ \\
\hline PPA2239 & $\begin{array}{l}\text { putative peptidase/glycosyl } \\
\text { hydrolase }\end{array}$ & $\begin{array}{l}\text { DUF348 superfamily; } \\
\text { G5 domain; C-terminus: DPBB_1 (RlpA-like } \\
\text { double-psi beta-barrel); Janibacter }\end{array}$ & $\mathrm{SP}$ & $\begin{array}{l}|\mathrm{A},| \mathrm{B}, \\
\|,|| \mid\end{array}$ & $\begin{array}{l}++/ G 5: \text { a potential N- } \\
\text { acetylglucosamine } \\
\text { recognition domain }\end{array}$ \\
\hline
\end{tabular}

At least three of the five $P$. acnes strains secrete the listed proteins; see additional file 2 for a complete list of identified proteins. Re-annotation was performed for each gene. ${ }^{a}$ SP, signal peptide; TAT, twin-arginine motif; ${ }^{b}$ Semi-quantification based on Coomassie stained gels

\section{CAMP factors and other secreted proteins}

A set of five highly similar P. acnes genes (PPA687, PPA1198, PPA1231, PPA1340, PPA2108) in the genome of $P$. acnes KPA encodes homologs to Christie-AtkinsMunch-Petersen (CAMP) factors, which are co-haemolytic proteins, found mainly in streptococcal species $[25,44,45]$. CAMP factors have been characterized as pathogenic determinants that exert lethal effects when administered to rabbits and mice [46]. In addition, streptococcal CAMP factors have been reported to act as pore-forming toxins [47]. In agreement with previous work [45], all P. acnes strains examined here were positive for the co-haemolytic CAMP reaction (data not shown). Our secretome data showed that all tested $P$. acnes strains secreted CAMP2 (PPA0687). In addition, the skin isolate KPA secreted CAMP4 (PPA1231). 
Secretion of the other three CAMPs was not observed in any strain using our approach. A previous study reported variable production of CAMP factors in different $P$. acnes isolates, as detected by western blotting experiments using different anti-CAMP sera [45]; the authors reported an abundance of CAMP1 in type IB and II strains. We did not find CAMP1 among the secreted proteins; a discrepancy that could be due to the detection limits of the different techniques used, i.e. our MS analysis detects the most prominently secreted factors, whereas immunoblotting is a more sensitive technique.

A key enzyme of glycolysis, GAPDH, was also secreted by three out of the five $P$. acnes strains tested. At first glance it is peculiar why a glycolysis enzyme should be secreted; however, a number of studies have identified GAPDH as an anchorless, multifunctional protein, displayed on the surface of several fungi and Gram-positive pathogens, which contributes to adhesion and virulence $[48,49]$. In Streptococcus pyogenes, this cell-associated and soluble protein is also known as streptococcal surface dehydrogenase (SDH) and as a plasmin receptor (Plr); its complement C5a-binding activity was shown to play a role in evasion of neutrophil recruitment to sites of infection [50]. Moreover, in S. agalactiae, GAPDH is an immunomodulatory factor, exhibiting B lymphocytestimulatory activity [51]

In addition to the above-mentioned proteins, several (conserved) hypothetical secreted proteins were detected. Three of these hypothetical proteins are encoded by a gene cluster (PPA0532-0534), with homologs only in Corynebacterium spp. Three additional secreted proteins (PPA1715, PPA1939, PPA2175) are unique to $P$. acnes; PPA1715 contains characteristic repeats of the dipeptide proline-threonine (PT), similar to other putative adhesins (discussed below), and PPA1939 was secreted most strongly by all tested strains. Future work will determine the function of this abundantly secreted protein.

\section{Strain-specific secretion of putative adhesions}

As expected, the secretomes of the type IB strains, KPA and P6, share a higher degree of similarity with each other than with the other three strains tested. Nevertheless, we identified a few prominent differences between KPA and P6: (i) KPA secreted both CAMP4 and CAMP2. By contrast, P6 exclusively secreted CAMP2; (ii) KPA was the only strain which secreted PPA2141, a protein unique to $P$. acnes and with no homology to proteins stored in any database. A likely explanation for the KPA-specific expression of the gene encoding PPA2141 is a duplication of a 12 bp repeat within the 5 '-end of the gene in strains 266 and P6 (Fig. 3A). This duplication results in the insertion of four amino acids just after the predicted cleavage site of the signal peptide, which potentially alter secretion; (iii) likewise, PPA1880, which also has no existing homology to other proteins but contains characteristic PT repeats (Fig. 3B), was secreted exclusively by P6. Interestingly, PPA1880 possesses a phase variation-like signature - a stretch of guanine residues, located within the putative promoter region. Sequencing of the upstream region of PPA1880 revealed a variable number of guanine residues in the three strains (11 nt in P6, 13 nt in KPA and 15 nt in 266) (Fig. 3C). Changes in the number of guanine residues alter the length of the spacer region of the putative promoter. Thus, observed differences in spacer lengths 18 nt in P6 (close to the consensus length), $20 \mathrm{nt}$ in KPA and 23 nt in 266 - may explain why PPA 1880 expression is P6-specific. Alternatively, if the guanine tract is assumed to be part of the $\mathrm{N}$-terminus of PPA1880, frameshifts leading to truncated proteins would be introduced in KPA and 266, but not in P6 (additional file 3).

A number of major differences were detected between strains belonging to phylotypes IA and IB: In comparison to the two type IB strains (KPA and P6), strain 266, a type IA strain, exhibited (i) reduced lysozyme (PPA1662) secretion, and (ii) increased secretion of the lipase GehA; (iii) in addition, strain 266 exclusively secreted PPA2127. PPA2127 (also designated PA-25957) is a host cell-surface attachment protein with dermatansulphate-binding activity and has immunoreactive properties [26]. The corresponding gene is associated with a putative phase variation signature; variable expression in different $P$. acnes strains has been observed and attributed to mutated start codons or alterations in the length of the homopolymeric cytosine tract in the $5^{\prime}$-end of the gene [26]. Comparison of PPA2127 gene sequences from KPA, P6 and 266 revealed that the start codon was mutated in KPA. In strain P6 the length of the cytosine tract was altered, leading to a frameshift and the introduction of a premature stop codon (Fig. 3D). In addition, the number of $\mathrm{PT}$ repeats within the $\mathrm{C}$-terminus of PPA2127 varied. These repeats were more numerous in strain 266 as compared to the two type IB strains (Fig. 3E).

Strain 329, a type II strain, secreted a few proteins (Fig. 1D, spots 39-41) which could not be assigned to any known protein. MALDI-MS identification and subsequent homology searches against the genomes of $P$. acnes and the whole NCBI database retrieved no significant matches, indicating that these proteins are unique to strain 329.

Strain 487, a type III strain, secreted fewer factors than any of the other strains. One protein, PPA1758, an outer membrane lipoprotein of the periplasmic binding proteins (PBPs) superfamily, was secreted solely by 


\begin{tabular}{|c|c|}
\hline \multicolumn{2}{|c|}{ A) } \\
\hline \multirow{2}{*}{ A) } & $\begin{array}{lllllllll}S & A & P & A & K & P & G & I\end{array}$ \\
\hline & 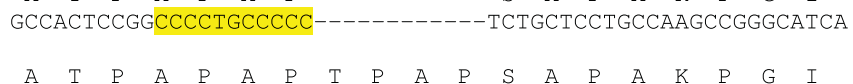 \\
\hline P 6 & GCCACTCCGGCCCCTGCCCCCACCCCTGCCCCCTCTGCTCCTGCCAAGCCGGGCATCA \\
\hline 266 & $\begin{array}{ccccccccccccccccccc}A & \mathrm{~T} & \mathrm{P} & \mathrm{A} & \mathrm{P} & \mathrm{A} & \mathrm{P} & \mathrm{T} & \mathrm{P} & \mathrm{A} & \mathrm{P} & \mathrm{S} & \mathrm{A} & \mathrm{P} & \mathrm{A} & \mathrm{K} & \mathrm{P} & \mathrm{G} & \mathrm{I} \\
\text { GCCACTCCGGCCCCTGCCCCCACCCCTGCCCCCTCTGCTCCTGCCAAGCCGGGCATCA }\end{array}$ \\
\hline & 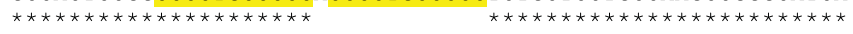 \\
\hline
\end{tabular}

B)

$\begin{array}{ll}\text { KPA } & \text { AGYLLSGDTPKPTPTPTPTPTPTPTPKP TP TP TPAPTSGEATVKPVPGAAT } \\ \text { P6 } & \text { AGYLLSDTPKPTPTPTPTPTPTPTPKPTPTPTPAPTSGEATVKPVGAAT } \\ 266 & \text { AGYLLSGDTPKPTPTPTPTPTPTPTPKPTPTPTPAPTSGEATVKPVPGAT }\end{array}$

266 AGYLLSGDTPKPTPTPTPTPTPTPTPKPTPTPTPAPTSGEATVKPVPGAAT

C)

D) AGGCAGAAGC

Figure 3 Changes in repetitive sequences involved in strain-specific expression and secretion of putative adhesins of $P$. acnes. (a) Insertion of a 12 bp repeat in the 5'-end of PPA2141 in P. acnes strains P6 and 266 results in an altered N-terminus. PPA2141 is secreted only by strain KPA. (b) Proline-threonine (PT) repeats at the C-terminus of PPA1880; these repeats are conserved in the indicated P. acnes strains. (c) Changes in the number of guanine residues in the upstream region of PPA1880, resulting in altered sizes of the spacer region of the possible promoter (in green: putative -35 and -10 region of the promoter; in red: predicted start codon). An alternative consequence of these alterations is shown in Fig. S2. PPA1880 is only secreted by strain P6. (d) Sequence differences of PPA2127: mutated start codon in strain KPA and variation of the C tract in the $5^{\prime}$ end of the gene. PPA2127 is only secreted by strain 266. (e) Different numbers of PT repeats at the C-terminus of PPA2127. 
strain 487 . PPA1758 exhibits a $38 \%$ protein identity to the membrane-associated glycylmethionine binding protein (GmpC) of Staphylococcus aureus [52], indicating a potential role as a dipeptide transporter for PPA1758.

\section{Secretome of $P$. acnes $\mathbf{2 6 6}$ in stationary growth phase}

To investigate growth phase-dependent secretion, $P$. acnes was grown to stationary phase. We selected strain 266 for this analysis as it was found to aggregate strongly upon reaching the stationary phase (additional file 4). 2-DE/MALDI-MS analysis of strain 266 culture supernatants revealed approximately half of the identified spots (33 out of 65) corresponded to proteins already identified as being secreted during the midexponential phase (Fig. 4 and additional file 5). The other spots corresponded to proteins mainly involved in key metabolic pathways and that are known to be primarily located in the bacterial cytoplasm. Thus, it is most likely that lysis of $P$. acnes occurred in the stationary phase, releasing the most abundant cytosolic proteins. Enzymes of key pathways such as glycolysis, pyruvate metabolism and the tricarboxylic acid cycle were identified, including phosphoglyceromutase, phosphoglycerate kinase, oxaloacetate decarboxylase, fumarate hydratase, and succinyl-CoA synthetase. In addition, we detected amino acid-converting proteins, i. e. serine hydroxymethyltransferase, tryptophanase and ornithine carbamoyltransferase. Other identified proteins included elongation factors, catalase, $10 \mathrm{kDa}$ chaperonin

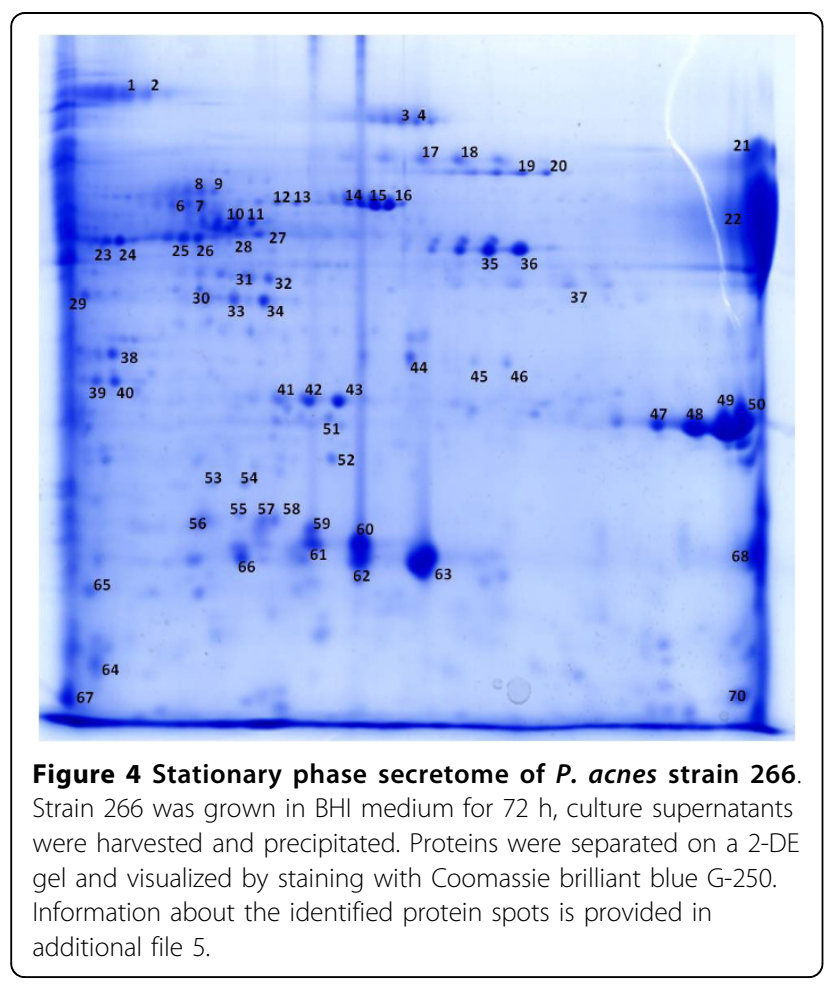

as well as the fatty acid biosynthesis enzyme acyl-carrier-protein S-malonyltransferase. Only two proteins with a typical signal peptide, which were not detected in the exponential phase-secretome, were identified: PPA2152, an extracellular solute-binding protein, and PPA2210, another protein containing a long stretch of PT repeats. PPA2210, designated as dermatan-binding protein PA-5541, was previously identified as being immunoreactive [26] and shares many properties with the above-mentioned protein PPA2127 (PA-25957). To unambiguously identify the stationary phase secretome of $P$. acnes future work is required to reduce the number of 'contaminating' (i.e. cytoplasmic) proteins; for instance, the choice of the culture medium might influence cell lysis. In addition, it is necessary for comparative reasons to determine the complete proteome of the cytoplasmic fraction.

\section{Conclusions}

Despite the ubiquitous presence of $P$. acnes, our knowledge of this bacterium remains limited, in particular regarding the factors allowing its growth on human tissues. Many studies have shown that $P$. acnes has the ability to act as an opportunistic pathogen, with suggested etiological roles in a variety of inflammatory diseases. Due to its immune-stimulatory activity, it seems plausible that $P$. acnes causes inflammation within blocked sebaceous follicles or when it grows in tissue sites unaccustomed and/or hostile to this anaerobic bacterium. Hence, the ability of $P$. acnes to acquire and process growth substrates from its host, especially in the harsh environment of human skin, is dependent on the factors this bacterium secretes. The detection and identification of such factors are therefore important steps in further understanding $P$. acnes pathogenesis. Our study has highlighted the prevalence of secreted hydrolases likely to be involved in degrading human tissue components. Other identified proteins such as immunoreactive adhesins have a putative role in virulence. Secreted factors may also fulfill other functions such as defending against competing organisms and the evasion of the immune response. Functional characterization of these secreted factors is a necessary and logical next step, which requires the development of appropriate tools, e.g. a mutagenesis approach to create $P$. acnes knock-out mutants. Another challenge for the future lies in the elucidation of the molecular basis for observed differences in virulence between $P$. acnes isolates. The relationship between phylotypes (based on recA/tly sequences) and strain properties remains obscure; some properties, for instance the ability to trigger production of proinflammatory cytokines/chemokines in keratinocytes, seem to be phylotype-specific $[21,22]$, whereas other properties, e.g. biofilm formation, 
are not [53]. Recent work has shown that an extended typing method based on serotyping in tandem with sequence comparison of three genes (trigger factor, p60, and mce) could distinguish invasive from non-invasive $P$. acnes isolates [54]; thus, this approach may be more appropriate for typing $P$. acnes isolates. In addition, our secretome analyses has revealed differences not only between but within phylotypes. A more extensive comparative analysis of $P$. acnes isolates incorporating robust phylotype identification will help to further our understanding of strain specificities.

\section{Methods}

\section{Bacteria and growth conditions}

The following $P$. acnes strains were used: 266 (type IA), P6 and KPA171202 (both type IB), 329 (type II), and 487 (type III). Strains 266, 329 and 487 were kindly provided by Oliver Knapp and Michel Popoff (Institut Pasteur). Strain KPA171202 was obtained from DSMZ (German German Collection of Microorganisms and Cell Cultures) and strain P6 was isolated from a cancerous prostate [55]. All P. acnes strains were cultured at $37^{\circ} \mathrm{C}$ on Brucella agar plates under anaerobic conditions for three days. Plate-grown bacteria were resuspended and washed in brain heart infusion (BHI) broth. Twenty $\mathrm{ml}$ BHI broth was inoculated with $P$. acnes $\left(\mathrm{OD}_{600} 0.01\right)$ and grown for $12-72 \mathrm{~h}$ at $37^{\circ} \mathrm{C}$ and $160 \mathrm{rpm}$ in an anaerobic jar. After 14-18 h, the cultures typically reached the mid-exponential growth phase with an $\mathrm{OD}_{600}$ of 0.5 0.6. Stationary phase was obtained after $72 \mathrm{~h}$ of growth.

\section{Precipitation of extracellular proteins}

The exponential cultures were centrifuged for $15 \mathrm{~min}$ at $20,000 \times g$ and $4^{\circ} \mathrm{C}$, and the supernatant was filtered through a $0.22-\mu \mathrm{m}$-pore-size membrane filter to remove residual bacteria. Extracellular proteins were precipitated using a modified trichloroacetic acid (TCA) method as described previously [56]. In brief, the filtrate $(100 \mathrm{ml})$ was mixed with $100 \%$ TCA to a final concentration of $10 \%$ and incubated overnight at $4{ }^{\circ} \mathrm{C}$. The mixture was centrifuged for $30 \mathrm{~min}\left(20,000 \times g\right.$ and $\left.4^{\circ} \mathrm{C}\right)$ and the resulting pellet resuspended in $100 \mathrm{ml}$ of acetone and dissolved using an ultrasonic water bath. The mixture was centrifuged as before, washed twice with acetone and the resulting pellet air dried.

\section{Two-dimensional gel electrophoresis}

Protein samples were solubilized for $30 \mathrm{~min}$ at ambient temperature in $9 \mathrm{M}$ urea-1\% 3-[(3-cholamidopropyl)dimethylammonio]-1-propanesulfonate (CHAPS)-70 $\mathrm{mM}$ dithiothreitol (DTT)-2\% Servalyte 2-4 (Serva). Protein species were separated by a small-gel 2-DE system [57]. The samples containing $200 \mu \mathrm{g}$ of protein were applied to the anodic side of the isoelectric focusing gel containing ampholytes in the $\mathrm{pH}$ range $2-11$. The SDSPAGE of the second dimension was performed using $15 \%$ acrylamide gels $(7 \mathrm{~cm} \times 8 \mathrm{~cm})$. Protein spots were visualized by staining with Coomassie Brilliant Blue G$250[58]$.

\section{MALDI-MS}

Protein spots were identified by MALDI-MS after ingel tryptic digestion of excised spots [59]. The peptide mixture was solubilized in $1 \mu \mathrm{l} 33 \%$ acetonitrile/0.3\% trifluoroacetic acid. For MALDI-MS measurement, $0.25 \mu \mathrm{l}$ of the solubilized peptides were mixed with $0.75 \mathrm{ml}$ a-cyano-4-hydroxycinnamic acid (CHCA) and spotted onto a MALDI plate. A 4700 Proteomics Analyzer (Applied Biosystems) with a mass range of 800 $4000 \mathrm{Da}$ was used for MS and at least $3 \mathrm{MS} / \mathrm{MS}$ spectra were measured per spot. Peptide mass fingerprinting (PMF) and MS/MS data were searched against the complete NCBI Database (Version 20090513). Proteins were identified using MASCOT 2.1 http://www. matrixscience.com allowing a peptide mass tolerance of $30 \mathrm{ppm}$ and $\pm 0.3 \mathrm{Da}$ for the fragment mass tolerance. A maximum of one missed cleavage, oxidation of methionine, N-terminal acetylation of the peptide, propionamide at cysteine residues and N-terminal pyroglutamic acid formation were considered in these searches. The identification criteria were: minimum $30 \%$ sequence coverage; or minimum $15 \%$ sequence coverage and one MS/MS confirmation; or sequence coverage below $15 \%$ and at least two MS/MS confirmations.

\section{DNA isolation, PCR and sequencing}

DNA from P. acnes was isolated using the MasterPure ${ }^{\mathrm{TM}}$ Gram Positive DNA Purification Kit (Epicentre). Typing of $P$. acnes strains by $r e c A / t l y$ sequencing was performed as described previously [23]. For the analysis of the repetitive elements of PPA1880, PPA2127, and PPA2141 the PCR primers listed below were used to amplify 400 $500 \mathrm{bps}$ of the corresponding genomic region in strains P6, KPA and 266. PCR reactions were carried out using the Platinum Pfx DNA polymerase (Invitrogen), which has a proofreading $3^{\prime}-5^{\prime}$ exonuclease activity. PCR products were subsequently sequenced using the same primers. Primers: PPA1880_N_for CACTGTACGGAC AGGTCTGG, PPA1880_N_rev CCATCCATATCGCACTTGTC; PPA1880_C_for GGCCAGCGAGACC TCTGATT, PPA1880_C_rev GGATGGGCAACAATTC GATG; PPA2127_N_for ATTCTCTACACGGCATGAGC, PPA2127_N_rev ATCCAGCCTTAACCAAC GCA; PPA2127_C_for CAAGACTGCTGAGCAGCTCG, PPA2127 C rev GCCGATGGTGATCAGAATCC; PPA 2141_N_for CAACCTCGCTACGAAGTGGA, PPA2141 _N_rev GGTCCTTGAGAACGGTATCG. 


\section{Re-Annotation}

All identified proteins were re-annotated, i.e. homology searches against sequence databases such as GenBank, and protein-domain/family databases, i.e. Pfam and InterPro, were performed. Homologous proteins in other bacteria were only discussed if sequence similarity to $P$. acnes proteins exceeded $25 \%$ on the protein level, with an overlap of the query and subject sequence of at least $90 \%$.

\section{Accession numbers}

The sequences reported in this study were deposited in GenBank. Sequences of recA/tly for the typing of the five strains have accession numbers HM461111 to HM461117. Sequence data from PPA1880, PPA2141, and PPA2127 have accession numbers HM461118 to HM461123.

\section{List of abbreviations}

BHI: brain heart infusion; CAMP: Christie-AtkinsMunch-Petersen; GAPDH: glyceraldehyde 3-phosphate dehydrogenase; GehA: glycerol-ester hydrolase A; MALDI-MS: matrix-assisted-laser-desorption/ionization mass spectrometry; SP: signal peptide; TAT: twin-arginine translocation; 2-DE: two-dimensional gel electrophoresis.

\section{Additional material}

Additional file 1: Secreted proteins of different $P$. acnes strains Bacteria were grown in $\mathrm{BH}$ medium to an OD $(600 \mathrm{~nm})$ of 0.6 . Proteins in the culture supernatants were precipitated using 10\% TCA and separated on 2D-PAGE gels. (A) Second and (B) third replicate of the experiment shown in Figure 1

Additional file 2: MS-based identification of all protein spots originating from exponential phase culture supernatants of five $P$. acnes strains. This table lists all MS-identified proteins that were separated by 2-DE (see Figure 1).

Additional file 3: Alternative consequence of guanine stretch alterations upstream of PPA1880. The homopolymeric guanine stretch could be part of the N-terminus of PPA1880. The different lengths of the $G$ tract would lead to the formation of truncated proteins in strains KPA and 266 due to the appearance of a premature stop codon in the respective reading frame. Only in strain P6 a full protein would be synthesized.

Additional file 4: Adherence/agglutination of $P$. acnes strains grown to stationary phase. $2 \mathrm{ml} \mathrm{BHI}$ medium per well was inoculated with the indicated five $P$. acnes strains $\left(\mathrm{OD}_{600 \mathrm{~nm}} 0.01\right)$ and grown to stationary phase (72 h) under anaerobic conditions $\left(37^{\circ} \mathrm{C}, 110 \mathrm{rpm}\right)$. Strain 266 agglutinated stronger than the other strains. Shown are two independent experiments.

Additional file 5: MS-based identification of all protein spots originating from the stationary phase culture supernatant of $P$. acnes strain 266 . This table lists all MS-identified proteins that were separated by 2-DE (see Figure 4).

\section{Acknowledgements}

We thank Oliver Knapp and Michel Popoff (Institut Pasteur, Paris) for providing the $P$. acnes strains 266, 329 and 487, Meike Sörensen for excellent technical assistance, and Lesley A. Ogilvie and Lina Fassi Fehri for critical reading of the manuscript.

\section{Author details}

'Department of Molecular Biology, Max Planck Institute for Infection Biology, Berlin, Germany. ${ }^{2}$ Proteomics Core Facility, Max Planck Institute for Infection Biology, Berlin, Germany.

\section{Authors' contributions}

$\mathrm{CH}$ : protein sample preparations and data analyses; TNM: PCR analyses; UZA, MS, PRJ: 2-DE/MALDI-MS experiments and data analyses; $C H, P R J$, TFM: assisted in the design of the study, and critically read the manuscript; $H B$ : conceived and designed the study, analyzed data and wrote the manuscript. All authors read and approved the final manuscript.

Received: 2 April 2010 Accepted: 27 August 2010

Published: 27 August 2010

\section{References}

1. Cogen AL, Nizet V, Gallo RL: Skin microbiota: a source of disease or defence? Br J Dermatol 2008, 158:442-455.

2. Williams RE: Benefit and mischief from commensal bacteria. J Clin Pathol 1973, 26:811-818.

3. Bojar RA, Holland KT: Acne and Propionibacterium acnes. Clin Dermatol 2004, 22:375-379.

4. Kurokawa I, Danby FW, Ju Q, Wang X, Xiang LF, Xia L, et al: New developments in our understanding of acne pathogenesis and treatment. Exp Dermatol 2009, 18:821-832.

5. Mourelatos K, Eady EA, Cunliffe WJ, Clark SM, Cove JH: Temporal changes in sebum excretion and propionibacterial colonization in preadolescent children with and without acne. Br J Dermatol 2007, 156:22-31.

6. Wilcox HE, Farrar MD, Cunliffe WJ, Holland KT, Ingham E: Resolution of inflammatory acne vulgaris may involve regulation of CD4+ T-cell responses to Propionibacterium acnes. Br J Dermatol 2007, 156:460-465.

7. Dessinioti C, Katsambas AD: The role of Propionibacterium acnes in acne pathogenesis: facts and controversies. Clin Dermatol 2010, 28:2-7.

8. Govoni M, Colina M, Massara A, Trotta F: SAPHO syndrome and infections. Autoimmun Rev 2009, 8:256-259.

9. Jakab E, Zbinden R, Gubler J, Ruef C, von Graevenitz A, Krause M: Severe infections caused by Propionibacterium acnes: an underestimated pathogen in late postoperative infections. Yale J Biol Med 1996, 69:477-482.

10. Tanabe $T$, Ishige I, Suzuki $Y$, Aita $Y$, Furukawa A, Ishige $Y$, et al: Sarcoidosis and NOD1 variation with impaired recognition of intracellular Propionibacterium acnes. Biochim Biophys Acta 2006, 1762:794-801.

11. Alexeyev OA, Marklund I, Shannon B, Golovleva I, Olsson J, Andersson C, et al: Direct visualization of Propionibacterium acnes in prostate tissue by multicolor fluorescent in situ hybridization assay. J Clin Microbiol 2007, 45:3721-3728.

12. Cohen RJ, Shannon BA, McNeal JE, Shannon T, Garrett KL: Propionibacterium acnes associated with inflammation in radical prostatectomy specimens: a possible link to cancer evolution? J Urol 2005, 173:1969-1974

13. Shannon BA, Garrett KL, Cohen RJ: Links between Propionibacterium acnes and prostate cancer. Future Oncol 2006, 2:225-232.

14. Sutcliffe $S$, Giovannucci $E$, Isaacs WB, Willett WC, Platz EA: Acne and risk of prostate cancer. Int J Cancer 2007, 121:2688-2692.

15. Hoeffler U: Enzymatic and hemolytic properties of Propionibacterium acnes and related bacteria. J Clin Microbiol 1977, 6:555-558.

16. Csukas Z, Banizs B, Rozgonyi F: Studies on the cytotoxic effects of Propionibacterium acnes strains isolated from cornea. Microb Pathog 2004, 36:171-174.

17. Jappe U, Ingham E, Henwood J, Holland KT: Propionibacterium acnes and inflammation in acne; $P$. acnes has T-cell mitogenic activity. Br J Dermatol 2002, 146:202-209.

18. Jugeau S, Tenaud I, Knol AC, Jarrousse V, Quereux G, Khammari A, et al: Induction of toll-like receptors by Propionibacterium acnes. $\mathrm{Br} J$ Dermatol 2005, 153:1105-1113

19. Kim J, Ochoa MT, Krutzik SR, Takeuchi O, Uematsu S, Legaspi AJ, et al: Activation of toll-like receptor 2 in acne triggers inflammatory cytokine responses. J Immunol 2002, 169:1535-1541. 
20. Squaiella CC, Ananias RZ, Mussalem JS, Braga EG, Rodrigues EG, Travassos LR, et al: In vivo and in vitro effect of killed Propionibacterium acnes and its purified soluble polysaccharide on mouse bone marrow stem cells and dendritic cell differentiation. Immunobiology 2006, 211:105-116.

21. Nagy I, Pivarcsi A, Koreck A, Szell M, Urban E, Kemeny L: Distinct strains of Propionibacterium acnes induce selective human beta-defensin-2 and interleukin-8 expression in human keratinocytes through toll-like receptors. J Invest Dermatol 2005, 124:931-938.

22. Nagy I, Pivarcsi A, Kis K, Koreck A, Bodai L, McDowell A, et al: Propionibacterium acnes and lipopolysaccharide induce the expression of antimicrobial peptides and proinflammatory cytokines/chemokines in human sebocytes. Microbes Infect 2006, 8:2195-2205.

23. McDowell A, Valanne S, Ramage G, Tunney MM, Glenn JV, McLorinan GC, et al: Propionibacterium acnes types I and II represent phylogenetically distinct groups. J Clin Microbiol 2005, 43:326-334.

24. McDowell A, Perry AL, Lambert PA, Patrick S: A new phylogenetic group of Propionibacterium acnes. J Med Microbiol 2008, 57:218-224.

25. Brüggemann $H$, Henne $A$, Hoster $F$, Liesegang $H$, Wiezer $A$, Strittmatter $A$, et al: The complete genome sequence of Propionibacterium acnes, a commensal of human skin. Science 2004, 305:671-673.

26. Lodes MJ, Secrist H, Benson DR, Jen S, Shanebeck KD, Guderian J, et al: Variable expression of immunoreactive surface proteins of Propionibacterium acnes. Microbiology 2006, 152:3667-3681.

27. Bumann D, Aksu S, Wendland M, Janek K, Zimny-Arndt U, Sabarth N, et al: Proteome analysis of secreted proteins of the gastric pathogen Helicobacter pylori. Infect Immun 2002, 70:3396-3403.

28. Jungblut PR, Holzhutter $H G$, Apweiler R, Schluter $H$ : The speciation of the proteome. Chem Cent J 2008, 2:16-26.

29. Caines MEC, Vaughan MD, Tarling CA, Hancock SM, Warren RAJ, Withers SG, et al: Structural and mechanistic analyses of endo-glycoceramidase II, a membrane-associated family 5 glycosidase in the Apo and G(M3) ganglioside-bound forms. J Biol Chem 2007, 282:14300-14308.

30. Litzinger S, Duckworth A, Nitzsche K, Risinger C, Wittmann V, Mayer C: Muropeptide rescue in Bacillus subtilis involves sequential hydrolysis by beta- $\mathrm{N}$-acetylglucosaminidase and $\mathrm{N}$-acetylmuramyl-L-alanine amidase. J Bacteriol 2010, 192:3132-3143

31. Rau A, Hogg T, Marquardt R, Hilgenfeld R: A new lysozyme fold - Crystal structure of the muramidase from Streptomyces coelicolor at 1.65 angstrom resolution. J Biol Chem 2001, 276:31994-31999.

32. Kamisango K, Saiki I, Tanio Y, Okumura H, Araki Y, Sekikawa I, et al: Structures and biological activities of peptidoglycans of Listeria monocytogenes and Propionibacterium acnes. J Biochem 1982, 92:23-33.

33. Ingham E, Holland KT, Gowland G, Cunliffe WJ: Purification and partial characterization of hyaluronate lyase (EC 4.2.2.1) from Propionibacterium acnes. J Gen Microbiol 1979, 115:411-418.

34. Steiner B, Romero-Steiner S, Cruce D, George R: Cloning and sequencing of the hyaluronate lyase gene from Propionibacterium acnes. Can J Microbiol 1997, 43:315-321.

35. Lunin W, Li YG, Linhardt RJ, Miyazono H, Kyogashima M, Kaneko T, et al: High-resolution crystal structure of Arthrobacter aurescens chondroitin AC lyase: An enzyme-substrate complex defines the catalytic mechanism. J Mol Biol 2004, 337:367-386.

36. Whitesid JA, Voss JG: Incidence and lipolytic activity of Propionibacterium acnes (Corynebacterium acnes group I) and $P$. granulosum (C. acnes group II) in acne and in normal skin. J Invest Dermatol 1973, 60:94-97.

37. Falcocchio S, Ruiz C, Pastor FIJ, Saso L, Diaz P: Propionibacterium acnes GehA lipase, an enzyme involved in acne development, can be successfully inhibited by defined natural substances. J Mol Catal B Enzym 2006, 40:132-137.

38. Gloor M, Wasik B, Becker A, Hoffler U: Inhibition of lipase activity in antibiotic-resistant Propionibacterium acnes strains. Dermatology 2002, 205:260-264.

39. Miskin JE, Farrell AM, Cunliffe WJ, Holland KT: Propionibacterium acnes, a resident of lipid-rich human skin, produces a 33 kDa extracellular lipase encoded by gehA. Microbiology 1997, 143:1745-1755.

40. Burkhart CN, Burkhart CG: Microbiology's principle of biofilms as a major factor in the pathogenesis of acne vulgaris. Int J Dermatol 2003, 42:925-927.

41. Gribbon EM, Cunliffe WJ, Holland KT: Interaction of Propionibacterium acnes with skin lipids in vitro. J Gen Microbiol 1993, 139:1745-1751.
42. Jappe U: Pathological mechanisms of acne with special emphasis on Propionibacterium acnes and related therapy. Acta Derm Venereol 2003 83:241-248.

43. Lee WL, Shalita AR, Suntharalingam K, Fikrig SM: Neutrophil chemotaxis by Propionibacterium acnes lipase and its inhibition. Infect Immun 1982, 35:71-78.

44. Jiang M, Babiuk LA, Potter AA: Cloning, sequencing and expression of the CAMP factor gene of Streptococcus uberis. Microb Pathog 1996, 20:297-307.

45. Valanne S, McDowell A, Ramage G, Tunney MM, Einarsson GG, O'Hagan S, et al: CAMP factor homologues in Propionibacterium acnes: a new protein family differentially expressed by types I and II. Microbiology 2005, 151:1369-1379.

46. Skalka B, Smola J: Lethal effect of CAMP-factor and Uberis-factor - a new finding about diffusible exosubstances of Streptococcus agalactiae and Streptococcus uberis. Zentralbl Bakteriol A 1981, 249:190-194.

47. Lang SH, Palmer M: Characterization of Streptococcus agalactiae CAMP factor as a pore-forming toxin. J Biol Chem 2003, 278:38167-38173.

48. Bergmann S, Rohde M, Hammerschmidt S: Glyceraldehyde-3-phosphate dehydrogenase of Streptococcus pneumoniae is a surface-displayed plasminogen-binding protein. Infect Immun 2004, 72:2416-2419.

49. Pancholi $V$, Fischetti VA: A major surface protein on group $A$ streptococci is a glyceraldehyde-3-phosphate dehydrogenase with multiple binding activity. J Exp Med 1992, 176:415-426.

50. Terao Y, Yamaguchi M, Hamada S, Kawabata S: Multifunctional glyceraldehyde-3-phosphate dehydrogenase of Streptococcus pyogenes is essential for evasion from neutrophils. J Biol Chem 2006, 281:14215-14223.

51. Madureira P, Baptista M, Vieira M, Magalhaes V, Camelo A, Oliveira L, et al: Streptococcus agalactiae GAPDH is a virulence-associated immunomodulatory protein. J Immunol 2007, 178:1379-1387.

52. Williams WA, Zhang RG, Zhou M, Joachimiak G, Gornicki P, Missiakas D, et al: The membrane-associated lipoprotein- $9 \mathrm{GmpC}$ from Staphylococcus aureus binds the dipeptide GlyMet via side chain interactions. Biochemistry 2004, 43:16193-16202.

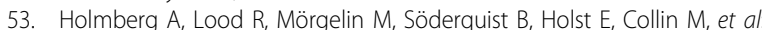
Biofilm formation by Propionibacterium acnes is a characteristic of invasive isolates. Clin Microbiol Infect 2009, 15:787-795.

54. Furukawa A, Uchida K, Ishige Y, Ishige I, Kobayashi I, Takemura T, et al: Characterization of Propionibacterium acnes isolates from sarcoid and non-sarcoid tissues with special reference to cell invasiveness, serotype, and trigger factor gene polymorphism. Microb Pathog 2009, 46:80-87.

55. Fassi Fehri L, Mak TN, Laube B, Brinkmann V, Ogilvie LA, Mollenkopf HJ, et al: Prevalence of Propionibacterium acnes in diseased prostates, and its inflammatory and transforming activity on prostate epithelial cells. Int J Med Microbiol

56. Komoriya K, Shibano N, Higano T, Azuma N, Yamaguchi S, Aizawa S Flagellar proteins and type III-exported virulence factors are the predominant proteins secreted into the culture media of Salmonella typhimurium. Mol Microbiol 1999, 34:767-779.

57. Jungblut PR, Seifert R: Analysis by high-resolution 2-dimensional electrophoresis of differentiation-dependent alterations in cytosolic protein pattern of HL60 leukemic cells. J Biochem Biophys Methods 1990 21:47-58.

58. Doherty NS, Littman BH, Reilly K, Swindell AC, Buss JM, Anderson NL: Analysis of changes in acute-phase plasma proteins in an acute inflammatory response and in rheumatoid arthritis using twodimensional gel electrophoresis. Electrophoresis 1998, 19:355-363.

59. Zimny-Arndt U, Schmid M, Ackermann R, Jungblut PR: Classical proteomics: two-dimensional electrophoresis/MALDI mass spectrometry. Methods Mol Biol 2009, 492:65-91.

doi:10.1186/1471-2180-10-230

Cite this article as: Holland et al:: Proteomic identification of secreted proteins of Propionibacterium acnes. BMC Microbiology 2010 10:230. 